\title{
Which Diagnostic Criteria of Metabolic Syndrome Can Better Predict the Risk of Ischemic Heart Disease and Stroke in Japanese and Asian Populations?
}

\author{
Katsutoshi OKADA ${ }^{1)}$
}

(Hypertens Res 2008; 31: 2103-2104)

Key Words: metabolic syndrome, follow-up study, Japanese, ischemic heart disease, stroke

Several different sets of diagnostic criteria for metabolic syndrome have been defined by the Third Report of the National Cholesterol Education Program Expert Panel on Detection and Treatment of High Blood Cholesterol in Adults (NCEPATP III) $(1,2)$, the American Heart Association and the National Heart, Lung and Blood Institute (AHA/NHLBI) (3), the International Diabetes Federation (IDF) (4) and the Japanese Committee to Evaluate Diagnostic Standards for Metabolic Syndrome (5). However, little is known about which set of diagnostic criteria may accurately predict the risk of cardiovascular disease in Asian populations.

In the previous issue of Hypertension Research, Chei et al. examined the associations between metabolic syndrome and risks of ischemic heart disease and stroke in a populationbased Japanese cohort study using different diagnostic criteria (6). The authors found that the NCEP-ATP III criteria for metabolic syndrome were better at predicting the risk of cardiovascular disease, ischemic heart disease and stroke than other sets of diagnostic criteria, probably due to the requirement for waist circumference. The other substantial studies among Japanese populations showed only an association between NCEP-ATP III criteria and cardiovascular disease $(7,8)$.

Metabolic syndrome had also been called syndrome X (9) or the deadly quartet (10), which implied insulin resistance (i.e., early phase of impaired glucose tolerance [IGT] and type 2 diabetes) $(2,11)$. The criteria of metabolic syndrome based on the definition above were practical because it is easy to diagnose the early phase of IGT and diabetes $(11,12)$. How- ever, metabolic syndrome was recently defined as one of the many independent risk factors (i.e., age, smoking habit and hypertension) for cardiovascular disease $(1-3,11-14)$. Some factors of metabolic syndrome may indirectly influence the risk of cardiovascular disease, thus weakening the predictive power for the risk of cardiovascular disease; for example, central obesity, which is a major component of metabolic syndrome, is a good predictor of diabetes risk, but may not be as good a predictor of cardiovascular disease risk (11). Thus, we must reconsider whether the criteria for metabolic syndrome are able to predict the risk of insulin resistance, the risk of cardiovascular disease, or both. If we focus on risks associated with metabolic syndrome in relation to cardiovascular disease, hypertension could be the most important required criterion for metabolic syndrome in Asian populations (15). In fact, Chei et al. analyzed a cluster of risk factors in cases and non-cases of cardiovascular disease and found a significant difference in hypertension, sex and age between cases and non-cases (6).

Nonetheless, we need more longitudinal studies to evaluate the diagnostic criteria for metabolic syndrome in Asian populations and these studies have to be continued because the prevalence of metabolic syndrome as well as other cardiovascular risk factors and diseases may continue to change.

\section{References}

1. Executive Summary of the Third Report of the National Cholesterol Education Program (NCEP) Expert Panel on

From the ${ }^{1)}$ Academic General Health Center, Ehime University, Matsuyama, Japan.

Address for Reprints: Katsutoshi Okada, M.D., Ph.D., Academic General Health Center, Ehime University, Dogo-himata, Matsuyama 790-8577, Japan.

E-mail: katokada@m.ehime-u.ac.jp

Received November 6, 2008. 
Detection, Evaluation, and Treatment of High Blood Cholesterol in Adults (Adult Treatment Panel III). JAMA 2001; 285: 2486-2497.

2. WHO Regional Office for the Western Pacific/International Association for the Study of Obesity/International Obesity Task Force: The Asia-Pacific Perspective: Redefining Obesity and Its Treatment. Sydney, Health Communications Australia, 2000.

3. Grundy SM, Cleeman JI, Daniels SR, et al: Diagnosis and management of the metabolic syndrome: an American Heart Association/National Heart, Lung, and Blood Institute Scientific Statement. Circulation 2005; 112: 27352752.

4. Alberti KG, Zimmet P, Shaw J: Metabolic syndrome-a new world-wide definition. A Consensus Statement from the International Diabetes Federation. Diabet Med 2006; 23: 469-480.

5. Definition and the diagnostic standard for metabolic syndrome - Committee to Evaluate Diagnostic Standards for Metabolic Syndrome. Nippon Naika Gakkai Zasshi 2005; 94: 794-809 (in Japanese).

6. Chei CL, Yamagishi K, Tanigawa T, et al: Metabolic syndrome and the risk of ischemic heart disease and stroke among middle-aged Japanese. Hypertens Res 2008; 31: 1887-1894.

7. Ninomiya T, Kubo M, Doi Y, et al: Impact of metabolic syndrome on the development of cardiovascular disease in a general Japanese population: the Hisayama study. Stroke 2007; 38: 2063-2069.

8. Takeuchi H, Saitoh S, Takagi S, et al: Metabolic syndrome and cardiac disease in Japanese men: applicability of the concept of metabolic syndrome defined by the National Cholesterol Education Program-Adult Treatment Panel III to Japanese men - the Tanno and Sobetsu Study. Hypertens Res 2005; 28: 203-208.

9. Reaven GM: Banting lecture 1988. Role of insulin resistance in human disease. Diabetes 1988; 37: 1595-1607.

10. Kaplan NM: The deadly quartet. Upper-body obesity, glucose intolerance, hypertriglyceridemia, and hypertension. Arch Intern Med 1989; 149: 1514-1520.

11. Kahn R, Buse J, Ferrannini E, Stern M: The metabolic syndrome: time for a critical appraisal: joint statement from the American Diabetes Association and the European Association for the Study of Diabetes. Diabetes Care 2005; 28: 2289-2304.

12. Alberti KG, Zimmet P, Shaw J: International Diabetes Federation: a consensus on type 2 diabetes prevention. Diabet Med 2007; 24: 451-463.

13. Brunzell JD, Davidson M, Furberg CD, et al: Lipoprotein management in patients with cardiometabolic risk: consensus statement from the American Diabetes Association and the American College of Cardiology Foundation. Diabetes Care 2008; 31: 811-822.

14. Mancia G, De Backer G, Dominiczak A, et al: 2007 Guidelines for the Management of Arterial Hypertension: the Task Force for the Management of Arterial Hypertension of the European Society of Hypertension (ESH) and of the European Society of Cardiology (ESC). J Hypertens 2007; 25: 1105-1187.

15. Shimamoto T, Kitamura A, Sato S, Konishi M, Iso H: Is this national project effective to keep and promote our health? Nippon Rinsho 2008; 66: 1413-1422 (in Japanese). 